\title{
Poor Vitamin D Status in Active Pulmonary Tuberculosis Patients and Its Correlation with Leptin and TNF- $\alpha$
}

\author{
Qiuzhen $\mathrm{WANG}^{1}$, Aiguo $\mathrm{MA}^{1}$, Tianlin $\mathrm{GAO}^{1}$, Yufeng $\mathrm{LIU}^{2}$, Lisheng REN ${ }^{3}$, Lei HAN ${ }^{3}$, \\ Boyang WEI ${ }^{1}$, Qian $\mathrm{LIU}^{1}$, Chunjiang DoNG ${ }^{1}$, Yuze Mu${ }^{1}$, Duo LI ${ }^{1}$, \\ Frans J KOK ${ }^{4}$ and Evert G SCHOUTEN ${ }^{4}$ \\ ${ }^{1}$ Institute of Human Nutrition, Medical College of Qingdao University, Qingdao, China \\ ${ }^{2}$ Qingdao Chest Hospital, Chongqing Middle Road, Qingdao, China \\ ${ }^{3}$ The Affiliated Hospital of Qingdao University, Qingdao, China \\ ${ }^{4}$ Division of Human Nutrition, Wageningen University, Wageningen, The Netherlands
}

(Received February 12, 2019)

\begin{abstract}
Summary Vitamin D deficiency (VDD) is common in tuberculosis (TB) and may be implicated in the etiology of the disease and in its clinical course. The aim of this study was to investigate the association between leptin, inflammatory markers and VD status in TB patients, stratified for presence or absence of diabetes mellitus (DM). Two hundred ninety-nine TB patients were recruited from October 2015 to August 2016. Also, 91 normal controls were included. The information including socio-demographics, dietary intake and living habits was obtained by face-to-face interview. Serum concentrations of leptin and TNF- $\alpha$, CRP and IL- 6 were compared between TB patients with and without severe VDD (SVDD). Pearson's correlation was used to analyze the association between TNF- $\alpha$, leptin and 25-hydroxyvitamin D (25(OH)D). A significantly higher prevalence of VDD and SVDD was observed in TB patients compared with normal controls $(93.0 \%$ vs $70.3 \%, 65.9 \%$ vs $3.3 \%$ respectively). Concentration of leptin was significantly lower, while TNF- $\alpha$ higher in TB patients with SVDD compared to those without $(p<0.05)$. After adjustment for confounders, leptin was positively associated with $25(\mathrm{OH}) \mathrm{D}(r=0.210, p=0.002)$ with similar correlation in TB patients with DM $(r=0.240, p=0.020)$. A negative association between TNF- $\alpha$ and 25(OH)D was observed ( $r=-0.197, p=0.003)$, which was significant only in the subgroup without DM $(r=-0.304, p=0.001)$. Our findings indicate that a higher VD status in TB patients may be related to higher immune activity and less serious tissue damage, and that this relation is different according to presence or absence of DM co-morbidity.
\end{abstract}

Key Words serum 25(OH)D, leptin, TNF- $\alpha$, diabetes, tuberculosis, co-morbidity, immune activity, inflammatory markers

Tuberculosis (TB) continues to be a major public health problem. According to the global TB report (WHO), the epidemic was larger than previously estimated. There were a total of 10.4 million new TB cases worldwide in 2016, with China still ranking high among the epidemic countries (1). China is also facing a rapidly increasing incidence of diabetes mellitus (DM) in the past ten years (2). DM has been reported to triple the risk of active TB (3) and to result in poor response to anti-TB treatment (4). However, the underlying mechanisms are still uncertain.

In recent years, the non-skeletal function of vitamin D (VD) has aroused intense interest. VD was discovered to stimulate innate immunity during Mycobacterium tuberculosis (Mtb) infection resulting in control of $M t b$ proliferation inside macrophages $(5,6)$. It is also involved in the regulation of host cytotoxic T lymphocyte responses (7) and the differentiation of naive $\mathrm{T}$ cells to regulatory $\mathrm{T}$ cells, indicating a possible role in adaptive immunity during infections.

E-mail: kevin_1971@126.com
VD deficiency (VDD) is a global health problem (8). High prevalence of VDD has been documented in Europe, Southeast Asia (9), Middle East and South America (8), even in some areas with very sunny climates, such as Saudi Arabia and India $(10,11)$. High prevalence of VDD was reported in TB patients. A meta-analysis combining seven epidemiological studies showed a modest to strong association of VDD with tuberculosis risk, reporting serum vitamin D levels are 0.68 SD lower in people with tuberculosis compared to controls (12). Although still lacking solid evidence, VD supplementation was reported to accelerate sputum smear conversion and the resolution of inflammatory responses during tuberculosis treatment (13).

Cytokines play an important role as mediator in the interaction between immune cells (14). The production of pro-inflammatory cytokines such as TNF- $\alpha$ indicates an important immunity response against $M t b$ in the host (15). However, exacerbated inflammatory responses may lead to poor bacterial control and development of TB in the host (16). It was reported that a high level of TNF- $\alpha$ during the treatment may lead to deleterious 
effects in the tissues, while anti-TNF- $\alpha$ antibody during the treatment resulted in augmented bacterial clearance and attenuated lung pathology, which indicates TNF- $\alpha$ level may be a marker of exaggerated inflammation during TB course (17). VDD was reported to be correlated with increased production of pro-inflammatory cytokines (18), which indicates the possible mechanism of the role of VD in TB. Although a potential role for VD in modulation of the inflammatory response in TB patients has been suggested (13), most of the available evidence is provided by in vitro studies $(19,20)$, and direct proof of the correlation of inflammatory levels with VD status in active TB patients is still lacking.

Leptin, a "satiety" hormone predominantly secreted by adipose cells to help to regulate energy balance, is also involved in both innate immune and adaptive immunity (21-23). Falling leptin concentrations appeared to be responsible for reduced T-cell function during starvation (24). A recent meta-analysis of twelve case-control studies found serum leptin levels of healthy controls were markedly higher than those of pulmonary tuberculosis patients (25), and after treatment of TB plasma leptin levels were observed to increase (26). However, the correlation between leptin and VD in TB patients has not been reported until now.

It is now well established that chronic inflammation, indicated by modestly increased levels of cytokines, contributes to the development and progression of DM. Impaired immune function in diabetic patients, especially with respect to macrophage and $\mathrm{T}$ lymphocyte functions, play a key role in the defence against Mtb (27-29), contributing significantly to higher risk of TB in DM patients. It was reported that tuberculosis patients with diabetes had a different profile of circulating levels of cytokines compared with those without diabetes (30).

We hypothesize that there may exist certain correlations between inflammatory cytokines, leptin and VD status, which may underlie the mechanism of the immune-modulatory effects of VD in TB, and this correlation may differ depending on the presence or absence of comorbid diabetes. Therefore, we carried out this cross-sectional study in active TB patients with and without DM. At the same time, a normal control group was included to compare the possible correlation between inflammatory cytokines, leptin and VD status.

\section{MATERIALS AND METHODS}

Design and subjects. In this cross-sectional study, 299 active TB patients (178 TB without DM and 121 TB with DM) were recruited from Qingdao TB clinics from October 2015 to August 2016. Also, 91 normal controls undergoing routine medical examination were included from a general hospital in Qingdao. The diagnosis of TB was made according to standard clinical criteria in which clinical manifestations, sputum smear microscopy and chest radiography were the central components. Diagnosed TB patients registered for Directly Observed Treatment, Short Course (DOTS) before the start of TB treatment, aged 18-65 y were recruited. The diagnosis of DM was based on self-report by patients who had already taken anti-diabetic medicines, or on the results of fasting plasma glucose (FPG) at the routine admission biochemistry test according to WHO criteria (1990) for the classification of glucose tolerance. Non-insulin dependent diabetes were included in the present study. Volunteers were excluded if they were pregnant or HIV-positive, had cancer, severe cardiac, hepatic and kidney diseases or trauma in the last 3 mo, took VD supplements in the former $6 \mathrm{mo}$, had a current or previous medical condition or took medication affecting immune function or affecting VD status in the body.

This study was carried out in accordance with requirements documented in the Declaration of Helsinki. Ethical approval for this study was received from the Ethics Committee of Qingdao Disease Prevention and Control Centre (Qingdao, China), and informed consent was obtained from each subject. The study was registered in the Chinese Clinical Trial Registry (No. ChiCTR-IPR-15006395).

Questionnaires and anthropometrical measurements. Structured questionnaires were administered by faceto-face interview to all subjects to collect information of socio-demographics, previous health conditions or diseases and family disease history, as well as lifestyle habits including smoking, alcohol drinking and outdoor activity level.

Height and weight were measured without shoes and heavy clothing by trained investigators and body mass index (BMI) was calculated as body weight divided by height squared $\left(\mathrm{kg} / \mathrm{m}^{2}\right)$. The cut-off value for Chinese population (31) was used for the classification of underweight $(<18.5)$, normal weight (18.5-23.9), overweight and obesity $(\geq 24)$.

Biochemical detection and laboratory analyses. Blood samples were drawn from each subject between 6:30 am and 9:00 am after fasting for at least $12 \mathrm{~h}$ and an overnight rest. Venous blood was collected into vacutainer tubes and allowed to clot at room temperature for $30 \mathrm{~min}$. The coagulated blood was centrifuged to collect the serum. Glucose levels were measured by glucose oxidase method and lipid indexes including serum total cholesterol (TC), triglyceride (TG), high density lipoprotein cholesterol (HDL-C) and low-density lipoprotein cholesterol (LDL-C) were determined by enzymatic procedure. All the analysis were performed by an automatic biochemical analyzer. The rest serum was aliquoted into sterile microcentrifuge tubes, and stored at $-80^{\circ} \mathrm{C}$ until measurement of 25 -hydroxyvitamin D $[25(\mathrm{OH}) \mathrm{D}]$, leptin and inflammatory indexes of TNF- $\alpha$, IL-6 and CRP.

Serum 25(OH)D concentrations were measured as described before (32). Briefly, ${ }^{125}$ I radioimmunoassay (RIA) kit from DiaSorin Inc (Stillwater, USA) was used. The sensitivity of the assay was $1.5 \mathrm{ng} / \mathrm{mL}$. The interassay variability was $10.5 \%$ and the intra-assay variability was $8.2 \%$.

Leptin levels were determined by the method of radioimmunoassay (RIA, XH6080). The sensitivity of the 
Table 1. General characteristics of the participants (mean \pm SD).

\begin{tabular}{|c|c|c|c|}
\hline & TB patients $(n=299)$ & Control $(n=91)$ & $p$ \\
\hline Age & $45.14 \pm 16.45$ & $47.45 \pm 9.24$ & 0.203 \\
\hline Male, $n(\%)$ & $219(73.2)$ & $63(69.2)$ & 0.504 \\
\hline SBP & $123.60 \pm 17.08$ & $127.23 \pm 17.49$ & 0.083 \\
\hline DBP & $76.11 \pm 10.75$ & $79.06 \pm 12.27$ & 0.026 \\
\hline BMI & $22.03 \pm 3.41$ & $22.78 \pm 2.98$ & 0.068 \\
\hline $\mathrm{FPG}(\mathrm{mmol} / \mathrm{L})^{1}$ & $5.42,3.58$ & $4.86,0.55$ & 0.000 \\
\hline $\mathrm{TC}(\mathrm{mmol} / \mathrm{L})$ & $4.19 \pm 1.12$ & $4.76 \pm 0.56$ & 0.000 \\
\hline $\mathrm{TG}(\mathrm{mmol} / \mathrm{L})^{2}$ & $1.03 \pm 0.18$ & $0.88 \pm 0.15$ & 0.019 \\
\hline $\mathrm{HDL}-\mathrm{C}(\mathrm{mmol} / \mathrm{L})^{3}$ & $11.94 \pm 1.39$ & $14.45 \pm 1.26$ & 0.013 \\
\hline $\mathrm{LDL}-\mathrm{C}(\mathrm{mmol} / \mathrm{L})^{1}$ & $2.42,1.03$ & $2.71,0.73$ & 0.207 \\
\hline $\mathrm{TP}(\mathrm{g} / \mathrm{L})$ & $66.28 \pm 7.01$ & $74.16 \pm 3.84$ & 0.000 \\
\hline $\operatorname{ALB}(g / L)$ & $39.12 \pm 5.80$ & $45.97 \pm 2.44$ & 0.000 \\
\hline $\operatorname{ALT}(\mathrm{U} / \mathrm{L})^{3}$ & $15.59 \pm 2.35$ & $16.94 \pm 1.58$ & 0.382 \\
\hline $\operatorname{AST}(\mathrm{U} / \mathrm{L})^{1}$ & $15.00,11.00$ & $20.00,7.00$ & 0.000 \\
\hline GGT $(\mathrm{U} / \mathrm{L})^{3}$ & $32.80 \pm 2.07$ & $1.99 \pm 1.61$ & 0.000 \\
\hline BUN (mmol/L) & $4.73 \pm 2.69$ & $5.08 \pm 1.23$ & 0.242 \\
\hline $\mathrm{CRE}(\mathrm{mmol} / \mathrm{L})$ & $57.31 \pm 35.79$ & $62.60 \pm 13.05$ & 0.168 \\
\hline $\mathrm{Hb}(\mathrm{g} / \mathrm{L})$ & $126.64 \pm 18.99$ & $144.73 \pm 15.94$ & 0.000 \\
\hline WBC count ${ }^{3}$ & $6.52 \pm 1.44$ & $5.66 \pm 1.26$ & 0.001 \\
\hline NEUT count ${ }^{3}$ & $4.32 \pm 1.65$ & $3.10 \pm 1.36$ & 0.000 \\
\hline NEUT\% $\%$ & $67.92 \pm 12.65$ & $55.42 \pm 8.46$ & 0.000 \\
\hline LYM count & $0.51 \pm 0.61$ & $2.05 \pm 0.60$ & 0.000 \\
\hline LYM\% & $24.36 \pm 11.31$ & $35.57 \pm 7.65$ & 0.000 \\
\hline MONO count ${ }^{3}$ & $2.95 \pm 1.79$ & $3.40 \pm 1.36$ & 0.026 \\
\hline $\mathrm{MONO}^{3}$ & $4.50 \pm 1.93$ & $5.60 \pm 1.28$ & 0.000 \\
\hline $25(\mathrm{OH}) \mathrm{D}(\mathrm{ng} / \mathrm{mL})^{2}$ & $6.50 \pm 0.22$ & $17.21 \pm 0.14$ & 0.000 \\
\hline$<20 \mathrm{ng} / \mathrm{mL}, n(\%)$ & $278(93.0)$ & $64(70.3)$ & 0.000 \\
\hline$<10 \mathrm{ng} / \mathrm{mL}, n(\%)$ & 197 (65.9) & $3(3.3)$ & 0.000 \\
\hline
\end{tabular}

${ }^{1}$ Skewed distribution in the data, median and inter-quartile range were used for presentation and Mann-Whitney $U$ test was used to test the difference.

${ }^{2} \log \times 10$ transferred, and $10^{\mathrm{x}} / 10$ for presentation.

${ }^{3} \log$ transferred and $10^{\mathrm{x}}$ for presentation.

TB, tuberculosis; SBP, systolic blood pressure; DBP, diastolic blood pressure; BMI, body mass index; FPG, fasting plasma glucose; TC, total cholesterol; TG, triglyceride; HDL-C, high-density lipoprotein cholesterol; LDL-C, low-density lipoprotein cholesterol; TP, total protein; ALB, albumin; ALT, glutamate pyruvic transaminase; AST, aspartate aminotransferase; GGT, glutamyl transpeptidase; BUN, blood urea nitrogen; CRE, creatinine; Hb, hemoglobin; WBC, white blood cell; NEUT, neutrophils; MONO, monocyte; LYM, lymphocyte; 25(OH)D, 25-hydroxyvitamin D.

assay was $<0.4 \mathrm{ng} / \mathrm{mL}$. The inter-assay variability was $<10 \%$ and the intraassay variability was $<15 \%$, and the average recovery was 93-99\%. TNF- $\alpha$ and IL- 6 levels were also measured by ${ }^{125} \mathrm{I}$ radioimmunoassay kit. For TNF- $\alpha$, the sensitivity of the assay was $6 \mathrm{fmol} / \mathrm{mL}$; the inter-assay variability was $<10 \%$ and the intraassay variability was $<15 \%$. For IL- 6 , the sensitivity of the assay was $50 \mathrm{pg} / \mathrm{mL}$; the inter-assay variability was $<7 \%$ and the intra-assay variability was $<15 \%$. Serum levels of CRP were measured by immuno-turbidimetric assay.

Definition of VDD and SVDD. The current widely accepted vitamin D nutritional status evaluation criteria by the Institute of Medicine was used to define vitamin D deficiency (VDD) and severe vitamin D deficiency (SVDD) (33). Serum 25(OH)D $<20 \mathrm{ng} / \mathrm{mL}(50 \mathrm{nmol} / \mathrm{L})$ was defined as VDD, and serum $25(\mathrm{OH}) \mathrm{D}<10 \mathrm{ng} / \mathrm{mL}$ $(25 \mathrm{nmol} / \mathrm{L})$ was defined as SVDD.

Statistical analyses. Characteristics of TB patients and normal controls were presented, also the results of comparison between TB patients with and without SVDD, as well as TB patients with and without diabetes. Mean and standard deviation for continuous variables with normal distribution and proportions for categorical variables were reported. Median and inter-quartile range were used for the description if the continuous data that were not normally distributed based on the results of Kolmogorov-Smirnov test. If the data were normally distributed after $\log 10$ or $\ln$ transfer, anti$\log 10$ or anti-ln values were presented. Independentsamples $T$ test was used to determine the differences between the groups; for data not normally distributed or of unequal variance, rank sum test was performed. Spearman's correlation analysis was used to determine the relationships between serum leptin, TNF- $\alpha$ and $25(\mathrm{OH}) \mathrm{D}$, and these data were $\log 10$ - or $\ln$-transformed into normal distribution data for correlation analysis. Also, partial correlation analysis was used to adjust for 
Table 2. Characteristics of TB patients by presence of SVDD (mean \pm SD).

\begin{tabular}{|c|c|c|c|}
\hline & SVDD $(n=197)$ & Non-SVDD $(n=102)$ & $p$ \\
\hline Age & $44.79 \pm 16.75$ & $45.83 \pm 15.92$ & 0.605 \\
\hline Male, $n(\%)$ & $144(73.1)$ & $75(73.5)$ & 0.936 \\
\hline $\mathrm{SBP}(\mathrm{mmHg})$ & $124.16 \pm 16.87$ & $122.47 \pm 17.53$ & 0.424 \\
\hline DBP (mmHg) & $76.05 \pm 10.80$ & $76.24 \pm 10.69$ & 0.882 \\
\hline BMI & $22.03 \pm 3.29$ & $22.03 \pm 3.60$ & 0.997 \\
\hline$<18.5, n(\%)$ & $21(14.5)$ & $14(14.6)$ & 0.873 \\
\hline $18.5-23.9, n(\%)$ & $85(58.6)$ & $59(61.5)$ & \\
\hline$\geqq 24, n(\%)$ & $39(26.9)$ & $23(24.0)$ & \\
\hline $\mathrm{FPG}(\mathrm{mmol} / \mathrm{L})^{1}$ & $5.32,3.36$ & $5.84,4.10$ & 0.139 \\
\hline $\mathrm{TC}(\mathrm{mmol} / \mathrm{L})$ & $4.17 \pm 1.12$ & $4.21 \pm 1.13$ & 0.812 \\
\hline $\mathrm{TG}(\mathrm{mmol} / \mathrm{L})^{2}$ & $0.97 \pm 0.17$ & $1.14 \pm 0.18$ & 0.028 \\
\hline $\mathrm{HDL}-\mathrm{C}(\mathrm{mmol} / \mathrm{L})^{2}$ & $1.17 \pm 0.14$ & $1.24 \pm 0.14$ & 0.184 \\
\hline $\mathrm{LDL}-\mathrm{C}(\mathrm{mmol} / \mathrm{L})^{1}$ & $3.29,0.94$ & $2.49,1.09$ & 0.510 \\
\hline $\mathrm{Hb}(\mathrm{g} / \mathrm{L})$ & $125.66 \pm 19.13$ & $128.56 \pm 18.67$ & 0.219 \\
\hline $\mathrm{TP}(\mathrm{g} / \mathrm{L})$ & $66.37 \pm 6.46$ & $66.10 \pm 7.98$ & 0.756 \\
\hline ALB $(\mathrm{g} / \mathrm{L})$ & $38.89 \pm 5.49$ & $39.55 \pm 6.36$ & 0.357 \\
\hline LYM count & $1.50 \pm 0.58$ & $1.51 \pm 0.65$ & 0.950 \\
\hline LYM \% & $24.89 \pm 11.20$ & $23.28 \pm 11.52$ & 0.269 \\
\hline WBC count ${ }^{3}$ & $6.28 \pm 1.45$ & $6.99 \pm 1.40$ & 0.016 \\
\hline NEUT count & $4.69 \pm 2.80$ & $5.37 \pm 2.84$ & 0.063 \\
\hline NEUT\% $\%$ & $66.93 \pm 13.19$ & $69.92 \pm 11.28$ & 0.065 \\
\hline MONO count ${ }^{2}$ & $0.30 \pm 0.18$ & $0.27 \pm 0.17$ & 0.153 \\
\hline MONO $\%^{3}$ & $4.68 \pm 1.94$ & $4.15 \pm 1.89$ & 0.166 \\
\hline $25(\mathrm{OH}) \mathrm{D}(\mathrm{ng} / \mathrm{mL})^{2}$ & $4.08 \pm 1.73$ & $15.92 \pm 1.39$ & 0.000 \\
\hline Leptin $(\mathrm{ng} / \mathrm{mL})^{4}$ & $2.70 \pm 0.22$ & $3.70 \pm 0.19$ & 0.001 \\
\hline TNF- $\alpha(\mathrm{fmol} / \mathrm{mL})^{3}$ & $12.47 \pm 1.89$ & $9.68 \pm 2.11$ & 0.004 \\
\hline IL-6 $(\mathrm{pg} / \mathrm{mL})^{3}$ & $85.50 \pm 2.68$ & $90.78 \pm 2.06$ & 0.593 \\
\hline $\mathrm{CRP}(\mathrm{mg} / \mathrm{L})^{3}$ & $27.10 \pm 4.72$ & $27.54 \pm 5.06$ & 0.945 \\
\hline \multicolumn{4}{|l|}{ Outdoor activity } \\
\hline$>2 \mathrm{~h} / \mathrm{d}, n(\%)$ & $60(40.3)$ & $31(32.3)$ & 0.207 \\
\hline$<2 \mathrm{~h} / \mathrm{d}, n(\%)$ & $89(59.7)$ & $65(67.7)$ & \\
\hline Smoking history, n, (\%) & $48(24.4)$ & $38(37.3)$ & 0.020 \\
\hline Alcohol history, $n(\%)$ & $75(38.1)$ & $49(48.0)$ & 0.097 \\
\hline
\end{tabular}

${ }^{1}$ Skewed distribution in the data, median and inter-quartile range were used for presentation and Mann-Whitney $U$ test was used to test the difference.

${ }^{2} \log \times 10$ transferred, and $10^{\mathrm{x}} / 10$ for presentation.

${ }^{3} \log$ transferred, and $10^{\mathrm{x}}$ for presentation.

${ }^{4} \ln \times 10$ transferred, and $\mathrm{e}^{\mathrm{x}} / 10$ for presentation.

TB, tuberculosis; SBP, systolic blood pressure; DBP, diastolic blood pressure; BMI, body mass index; FPG, fasting plasma glucose; TC, total cholesterol; TG, triglyceride; HDL-C, high-density lipoprotein cholesterol; LDL-C, low-density lipoprotein cholesterol; Hb, hemoglobin; TP, total protein; ALB, albumin; WBC, white blood cell; NEUT, neutrophils; MONO, monocyte; LYM, lymphocyte; 25(OH)D, 25-hydroxyvitamin D; SVDD, severe vitamin D deficiency; CRP, C-reactive protein; IL-6, interleukin-6; TNF- $\alpha$, tumor necrosis factor-alpha.

the influence of BMI, age and gender. All statistics were performed using SPSS version 21.0 software (IBM SPSS Statistics 21). A $p$-value of $<0.05$ was considered statistically significant.

\section{RESULTS}

General characteristics of the participants

General characteristics of patients and controls are shown in Table 1. No significant difference between age and gender was observed between the two groups. TB patients had lower total protein $(\mathrm{g} / \mathrm{L})(66.28 \pm 7.01$ vs $74.16 \pm 3.84)$, albumin $(\mathrm{g} / \mathrm{L}) \quad(39.12 \pm 5.80$ vs $45.97 \pm 2.44), \quad$ hemoglobin $\quad(\mathrm{g} / \mathrm{L}) \quad(126.64 \pm 18.99$ vs $144.73 \pm 15.94)$, lymphocyte count $(0.51 \pm 0.61$ vs $2.05 \pm 0.60)$ and lymphocyte percentage (\%) (24.36 \pm 11.31 vs $35.57 \pm 7.65)$ compared with controls, indicating decreased nutritional status in $\mathrm{TB}$ patients. Serum 25(OH)D (ng/mL) in TB patients was significantly lower than normal controls $(6.50 \pm 0.22$ vs $17.21 \pm 0.14$ ), which was nearly $40 \%$ of the latter. The prevalence of VDD was higher $(93.0 \%$ vs $70.3 \%)$, and of SVDD much higher ( $65.9 \%$ vs $3.3 \%$ ) than in controls. Difference according to presence or absence of SVDD and DM As shown in Table 2, 299 TB patients were classified into two groups based on the cut-off value of SVDD (serum $25(\mathrm{OH}) \mathrm{D}<10 \mathrm{ng} / \mathrm{mL}$ ). Log normal distribution of the data was found for serum 25(OH)D, leptin, TNF$\alpha$, IL-6 and CRP. Leptin (ng/mL) concentration in SVDD 
Table 3. Basic characteristics of TB patients by presence of diabetes (mean \pm SD).

\begin{tabular}{|c|c|c|c|}
\hline & TB-nonDM $(n=178)$ & TB-DM $(n=121)$ & $p$ \\
\hline Age & $39.98 \pm 17.19$ & $52.74 \pm 11.77$ & $<0.001$ \\
\hline Male, $n(\%)$ & $122(68.5)$ & $97(80.2)$ & 0.026 \\
\hline $\mathrm{SBP}(\mathrm{mmHg})$ & $120.88 \pm 16.24$ & $127.61 \pm 17.56$ & 0.001 \\
\hline DBP (mmHg) & $75.09 \pm 10.78$ & $77.62 \pm 10.56$ & 0.047 \\
\hline BMI & $21.68 \pm 3.15$ & $22.49 \pm 3.68$ & 0.076 \\
\hline$<18.5, n(\%)$ & $27(14.9)$ & $17(14.0)$ & 0.262 \\
\hline $18.5-23.9, n(\%)$ & $113(63.4)$ & $67(55.1)$ & \\
\hline$\geqq 24, n(\%)$ & $38(21.6)$ & $37(30.8)$ & \\
\hline $\mathrm{FPG}(\mathrm{mmol} / \mathrm{L})^{1}$ & $5.02,0.78$ & $9.08,6.32$ & $<0.001$ \\
\hline $\mathrm{TC}(\mathrm{mmol} / \mathrm{L})$ & $4.06 \pm 0.99$ & $4.66 \pm 2.97$ & 0.017 \\
\hline TG $(\mathrm{mmol} / \mathrm{L})$ & $0.98 \pm 0.48$ & $1.60 \pm 1.55$ & $<0.001$ \\
\hline HDL-C (mmol/L) & $1.23 \pm 0.37$ & $1.32 \pm 0.98$ & 0.281 \\
\hline LDL-C $(\mathrm{mmol} / \mathrm{L})$ & $2.80 \pm 3.68$ & $2.40 \pm 0.91$ & 0.262 \\
\hline $25(\mathrm{OH}) \mathrm{D}(\mathrm{ng} / \mathrm{mL})^{2}$ & $5.61 \pm 2.23$ & $8.07 \pm 2.06$ & $<0.001$ \\
\hline Leptin $(\mathrm{ng} / \mathrm{mL})^{3}$ & $3.01 \pm 0.20$ & $2.98 \pm 0.23$ & 0.941 \\
\hline $\mathrm{TNF}-\mathrm{a}(\mathrm{fmol} / \mathrm{mL})^{4}$ & $12.53 \pm 1.94$ & $10.07 \pm 2.02$ & 0.009 \\
\hline IL-6 $(\mathrm{pg} / \mathrm{mL})^{4}$ & $88.36 \pm 2.45$ & $85.50 \pm 2.54$ & 0.766 \\
\hline $\mathrm{CRP}(\mathrm{mg} / \mathrm{L})^{4}$ & $16.52 \pm 4.80$ & $52.84 \pm 3.69$ & $<0.001$ \\
\hline
\end{tabular}

\footnotetext{
${ }^{1}$ Skewed distribution in the data, median and inter-quartile range were used for presentation and Mann-Whitney $U$ test was used to test the difference.

${ }^{2} \log \times 10$ transferred, and $10^{\mathrm{x}} / 10$ for presentation.

${ }^{3} \ln \times 10$ transferred, and $\mathrm{e}^{\mathrm{x}} / 10$ for presentation.

${ }^{4} \log$ transferred, and $10^{\mathrm{x}}$ for presentation.

TB, pulmonary tuberculosis patients without diabetes; TB-DM, pulmonary tuberculosis patients with diabetes mellitus; SBP, systolic blood pressure; DBP, diastolic blood pressure; BMI, body mass index; FPG, fasting plasma glucose; TC, total cholesterol; TG, triglyceride; HDL-C, high density lipoprotein cholesterol; LDL-C, low density lipoprotein cholesterol; 25(OH)D, 25-hydroxyvitamin D; TNF- $\alpha$, tumor necrosis factor-alpha; CRP, C-reactive protein.
}

group was significantly lower than in non-SVDD group $(2.70 \pm 0.22$ vs $3.70 \pm 0.19, p=0.0001)$, while TNF- $\alpha$ $(\mathrm{fmol} / \mathrm{mL})$ concentration was higher in SVDD group $(12.47 \pm 1.89$ vs $9.68 \pm 2.11, p=0.004)$. No obvious differences were observed in IL- 6 and CRP levels.

When stratified by the presence of DM, 121 TB patients with DM (TB-DM) and 178 without DM (TBnonDM) were identified. Compared with TB-nonDM, TB-DM had higher levels of serum 25(OH)D $(\mathrm{ng} / \mathrm{mL})$ $(8.07 \pm 2.06$ vs $5.61 \pm 2.23, p<0.001)$. Significant difference of TNF- $\alpha(\mathrm{fmol} / \mathrm{mL})$ and CRP $(\mathrm{mg} / \mathrm{L})$ existed between them $(10.07 \pm 2.02$ vs $12.53 \pm 1.94, p=0.009$ and $52.84 \pm 3.69$ vs $16.52 \pm 4.80, p<0.001)$. No significant difference in leptin and IL- 6 was observed between the two groups. See in Table 3.

Relationship between serum leptin and 25(OH)D levels in active TB patients

Leptin concentrations were significantly positively correlated with serum 25(OH)D in TB patients $(r=0.246, p<0.001)$, which persisted after adjustment for BMI, age and gender $(r=0.210, p=0.002)$. Stratified analysis showed that serum leptin concentrations were both positively correlated with $25(\mathrm{OH}) \mathrm{D}$ in TB patients with and without DM $(r=0.240, r=0.182$, respectively). $R^{2}$-value in TB-DM was 0.104, which indicated $10.4 \%$ variation of serum leptin concentration could be explained by serum 25(OH)D. No significant correlation was observed between serum leptin and 25(OH)D in normal controls (Fig. 1)

Relationship between serum TNF- $\alpha$ and 25(OH)D levels in active TB patients

A negative correlation between TNF- $\alpha$ and serum $25(\mathrm{OH}) \mathrm{D}$ in active TB patients was observed $(r=-0.226$, $p<0.001$ ), which persisted after adjustment for BMI, age and gender $(r=-0.197, p=0.003)$. Further stratified analysis by presence of DM showed different profiles. The correlation was stronger in TB patients without DM $(r=-0.304, p=0.001)$, and $R^{2}$ value was 0.104 which indicating that serum 25(OH)D status explained 10.4\% of the variation in TNF- $\alpha$ concentrations. However, no such association was observed in TB-DM patients. The analysis of the correlation of TNF- $\alpha$ and $25(\mathrm{OH}) \mathrm{D}$ in normal controls gave no significant result (Fig. 2).

\section{DISCUSSION}

The present study demonstrates poor vitamin D (VD) status and a positive association between leptin and VD status in active TB patients, while the pro-inflammatory marker TNF- $\alpha$ was inversely correlated with VD. Furthermore, these correlations showed a different profile depending on presence or absence of comorbid DM, especially for TNF- $\alpha$.

In this observational study, the participants were recruited from a city level hospital in Qingdao, located in Shandong province in Eastern China. This hospital has a catchment area of about 9 million people, 

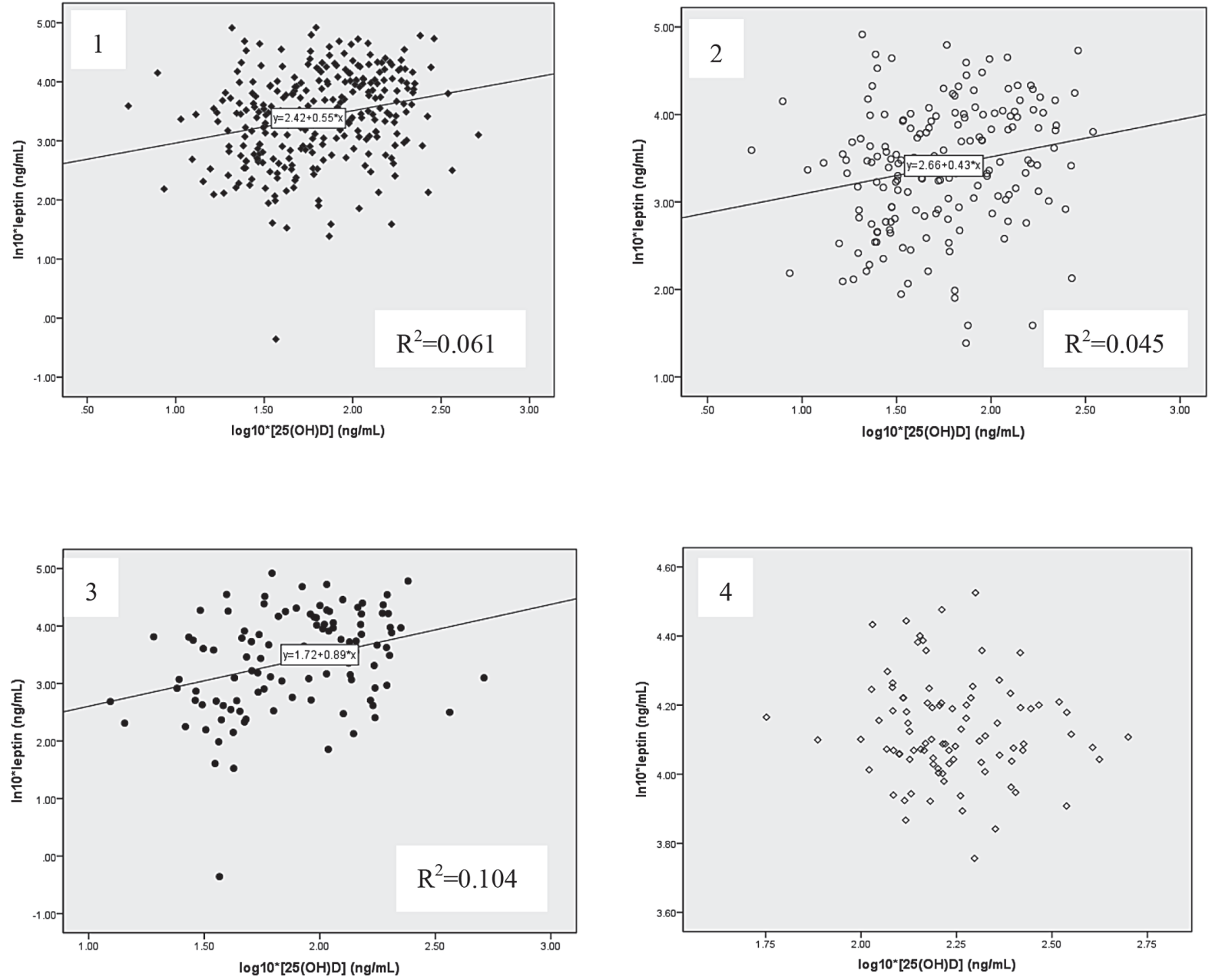

Fig. 1. Correlation between serum leptin and 25(OH)D concentrations. 1, all TB; 2, TB-nonDM; 3, TB-DM; 4, normal control. 25(OH)D was $\log 10$ transferred, and leptin was $\ln 10$ transferred.

and the average number of hospitalized patients with tuberculosis was about two thousand cases per year. A total of 299 active tuberculosis patients were randomly recruited, together with 91 normal controls randomly selected from persons undergoing physical check-up in a general hospital in the same city. No significant difference of age and gender existed between the patients and controls, which supports comparability. Since anti-TB treatment may significantly affect the circulating levels of leptin and inflammatory cytokines including TNF- $\alpha$, diagnosed TB patients before the start of chemotherapy were recruited in the present study which can reflect the authentic association between serum 25(OH)D and the target cytokines.

The most widely accepted criteria (33) were used to characterize the participants as VDD and SVDD in our study, i.e. cut off's for serum 25(OH)D of $20 \mathrm{ng} / \mathrm{mL}$ and $10 \mathrm{ng} / \mathrm{mL}$, respectively. Serum leptin and TNF- $\alpha$ levels were highly correlated with BMI (34), also age, gender may explain variance in their levels in the body (35, 36). These potential confounders were considered in the present study. Partial correlation analysis was used to adjust the possible confounding effect of these variables.

We observed a high prevalence of VDD (93.0\%) and
SVDD (65.9\%) in active tuberculosis patients, which was significantly lower than in normal controls $(70.3 \%$ and $3.3 \%$, respectively). Together with our previously reported study in a partly overlapping population (37), we might draw the conclusion that the VD status in active TB patients is very poor, especially in hospitalized patients.

Serum leptin levels were found to be positively correlated with $25(\mathrm{OH}) \mathrm{D}$ concentrations in TB patients in the present study, which was in accordance with the result of a cross-sectional study in a cohort of 259 Saudi normal adults (38). Leptin was reported to activate $\mathrm{T}$ lymphocytes via activating JAK-STAT signal pathway (39), together with the modification of Th1/Th2 balance, indicating its positive correlation with immune activity in the body. Low leptin levels may be a possible mediator of the association between severe weight loss and the suppressed cellular immunity $(39,40)$ in TB patients. Different to our result, an inverse association was claimed between leptin and $25(\mathrm{OH}) \mathrm{D}$ concentrations in a recent meta-analysis of 14 cross-sectional studies (41). However, most of the subjects included in this study were severely obese subjects, healthy persons or hemodialyzed patients, while no TB patients were 

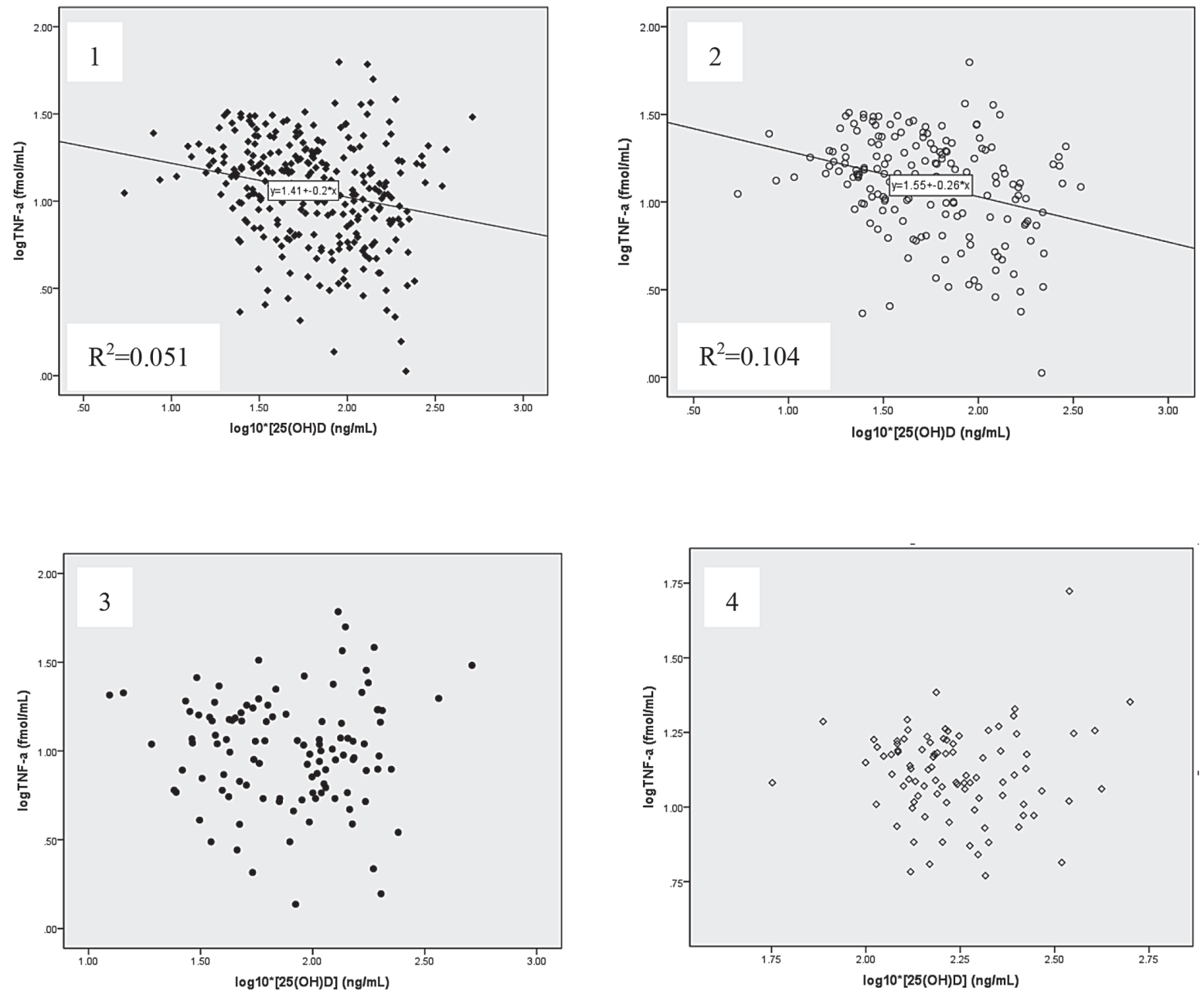

Fig. 2. Correlation between serum TNF- $\alpha$ with 25(OH)D concentrations. 1, all TB; 2, TB-non DM; 3, TB-DM; 4, normal control. 25(OH)D was $\log 10$ transferred, and TNF- $\alpha$ was $\log$ transferred.

included. The analysis stratified by DM showed similar results, while the correlation was somehow stronger in TB-DM patients. The possible reason may be that vitamin D is correlated with increased risk both of TB and $\operatorname{DM}(42,43)$, which may have resulted in a closer link between VD and leptin in patients with the combined disease. To our knowledge, this is the first time to report a positive relationship between leptin concentrations and VD status in active TB patients, and our result indicates that a possible favorable role of VD may be mediated by up-regulating leptin level.

Serum TNF- $\alpha$ concentrations was inversely related to $25(\mathrm{OH}) \mathrm{D}$ in TB-nonDM patients, and about $10 \%$ of the variation in TNF- $\alpha$ concentrations was explained by VD. TNF- $\alpha$, a pro-inflammatory cytokine secreted by macrophages, monocytes, T-cells and adipocytes, plays an important role in anti-TB immunity with a complex manifestation. Changes of TNF- $\alpha$ may be closely related to the progress of TB. A recent study claimed that TNF- $\alpha$ was correlated with TB severity, suggesting that it may be a marker of severity (44), and even a slight drop in circulating TNF- $\alpha$ may have clinical significance, indicating protection against excessive tissue damage at the site of infection (45). Till now, a few in vitro stud- ies about the correlations between TNF- $\alpha$ and VD in TB are available. 1,25-Dihydroxyvitamin D (1,25(OH)D) stimulation led to elevated levels of TNF- $\alpha$ in human monocyte-derived macrophages from TB patients (46). However, 1,25(OH)D was also reported to significantly suppress most $M t b$ antigen induced pro-inflammatory cytokines including TNF- $\alpha$. Notably, our stratified analysis showed that this inverse correlation did not exist in TB-DM patients. As we found in this study, co-existing DM presented with a different TNF- $\alpha$ level in TB patients. Similarly, increased inflammatory status was reported in TB-DM patients compared with TB (30). This may partially explain the different correlation between VD and TNF- $\alpha$ in TB-DM patients from those with only TB. Our result indicates that the down-regulation of TNF- $\alpha$ by vitamin D may contribute to its effects in TB patients.

The main strength of this study is that it provided renewed evidence on the correlation of inflammatory indexes and leptin with VD in TB patients in an in vivo situation. This may add valuable clues of the possible mechanism of the effect of VD in active TB patients. Also, the modification of comorbid DM was analyzed and a different profile of the associations was observed, especially with respect to TNF- $\alpha$. In the setting of dou- 
ble burden of TB and DM in developing countries in recent years, our study provides important data for the understanding of the characteristics of the diseases. Of course, the study has its limitations. We cannot make a convincing causal interpretation due to the cross-sectional design. In addition, despite adjustment for possible confounders in the data analysis, residual confounding cannot be completely ruled out. Also, only active TB patients were included in the present study, we could not ascertain whether the association between VD status and leptin, TNF- $\alpha$ also exist in latent tuberculosis. And the severity of TB manifestation may also influence this association, however, due to sample size in the present study, we cannot implement the stratified analysis. Nevertheless, the evidence with respect to the correlation of serum VD status with leptin and inflammatory biomarkers in active TB patients, and the heterogeneity observed in patients with and without DM is worthy of further investigation.

In conclusion, this study provides evidence that TNF- $\alpha$ in active TB patients is independently inversely correlated with circulating $25(\mathrm{OH}) \mathrm{D}$ concentration, while serum leptin levels show a positive correlation. This indicates that adequate VD status may lead to improved immune activity and less severe disease in TB. The underlying molecular mechanisms need further research. Enlarged sample size for the analysis stratified by the severity of TB, and similar study in latent tuberculosis are also needed in the future.

\section{Disclosure of state of COI}

No conflicts of interest to be declared.

\section{Acknowledgments}

We acknowledge all the co-investigators in the field work, and all the participants in this study. We thank for the support of the National Natural Science Foundation of China (NSFC) under Grant 81472983, and Medicine and health technology development project under Grant 2014 WS0166.

\section{REFERENCES}

1) World Health Organization. 2017. Global tuberculosis report 2017. Geneva.

2) Liu M, Liu S, Wang L, Bai Y, Zeng X, Guo H, Liu Y, Jiang Y, Dong W, He G, Zhou M, Shicheng Y. 2019. Burden of diabetes, hyperglycaemia in China from to 2016: Findings from the 1990 to 2016, global burden of disease study. Diabetes Metab 45: 286-293.

3) Jeon CY, Murray MB. 2008. Diabetes mellitus increases the risk of active tuberculosis: a systematic review of 13 observational studies. PLoS Med 5: e152.

4) Baker MA, Harries AD, Jeon CY, Hart JE, Kapur A, Lonnroth K, Ottmani SE, Goonesekera SD, Murray MB. 2011. The impact of diabetes on tuberculosis treatment outcomes: a systematic review. BMC Med 9: 81.

5) van der Does AM, Bergman P, Agerberth B, Lindbom L. 2012. Induction of the human cathelicidin LL-37 as a novel treatment against bacterial infections. J Leukoc Biol 92: $735-742$.

6) Wang TT, Nestel FP, Bourdeau V, Nagai Y, Wang Q, Liao J, Tavera-Mendoza L, Lin R, Hanrahan JW, Mader S, White
JH. 2004. Cutting edge: 1,25-dihydroxyvitamin D3 is a direct inducer of antimicrobial peptide gene expression. J Immunol 173: 2909-2912.

7) Sarkar S, Hewison M, Studzinski GP, Li YC, Kalia V. 2016. Role of vitamin D in cytotoxic T lymphocyte immunity to pathogens and cancer. Crit Rev Clin Lab Sci 53: 132-145.

8) Gonzalez-Gross M, Valtuena J, Breidenassel C, Moreno LA, Ferrari M, Kersting M, De Henauw S, Gottrand F, Azzini E, Widhalm K, Kafatos A, Manios Y, Stehle P. 2012. Vitamin D status among adolescents in Europe: the Healthy Lifestyle in Europe by Nutrition in Adolescence study. Br J Nutr 107: 755-764.

9) Zhu Z, Zhan J, Shao J, Chen W, Chen L, Li W, Ji C, Zhao Z. 2012. High prevalence of vitamin D deficiency among children aged 1 month to 16 years in Hangzhou, China. BMC Public Health 12: 126.

10) BinSaeed AA, Torchyan AA, AlOmair BN, AlQadhib NS, AlSuwayeh FM, Monshi FM, AlRumaih FI, AlQahtani SA, AlYousefi N, Al-Drees A. 2015. Determinants of vitamin D deficiency among undergraduate medical students in Saudi Arabia. Eur J Clin Nutr 69: 1151-1155.

11) G R, Gupta A. 2014. Vitamin D deficiency in India: prevalence, causalities and interventions. Nutrients 6: $729-775$.

12) Nnoaham KE, Clarke A. 2008. Low serum vitamin D levels and tuberculosis: a systematic review and metaanalysis. Int J Epidemiol 37: 113-119.

13) Coussens AK, Wilkinson RJ, Hanifa Y, Nikolayevskyy V, Elkington PT, Islam K, Timms PM, Venton TR, Bothamley GH, Packe GE, Darmalingam M, Davidson RN, Milburn HJ, Baker LV, Barker RD, Mein CA, Bhaw-Rosun L, Nuamah R, Young DB, Drobniewski FA, Griffiths CJ, Martineau AR. 2012. Vitamin D accelerates resolution of inflammatory responses during tuberculosis treatment. Proc Natl Acad Sci USA 109: 15449-15454.

14) Zhang SY, Boisson-Dupuis S, Chapgier A, Yang K, Bustamante J, Puel A, Picard C, Abel L, Jouanguy E, Casanova JL. 2008. Inborn errors of interferon (IFN)-mediated immunity in humans: insights into the respective roles of IFN-alpha/beta, IFN-gamma, and IFN-lambda in host defense. Immunol Rev 226: 29-40.

15) Roach DR, Bean AG, Demangel C, France MP, Briscoe H, Britton WJ. 2002. TNF regulates chemokine induction essential for cell recruitment, granuloma formation, and clearance of mycobacterial infection. J Immunol 168: 4620-4627.

16) Cliff JM, Kaufmann SH, McShane H, van Helden $P$, O'Garra A. 2015. The human immune response to tuberculosis and its treatment: a view from the blood. Immunol Rev 264: 88-102.

17) Bourigault ML, Vacher R, Rose S, Olleros ML, Janssens JP, Quesniaux VF, Garcia I. 2013. Tumor necrosis factor neutralization combined with chemotherapy enhances Mycobacterium tuberculosis clearance and reduces lung pathology. Am J Clin Exp Immunol 2: 124-134.

18) Kokturk N, Baha A, Oh YM, Young Ju J, Jones PW. 2016. Vitamin D deficiency: What does it mean for chronic obstructive pulmonary disease (COPD)? a compherensive review for pulmonologists. Clin Respir J 12: 382-397.

19) Karthaus N, van Spriel AB, Looman MW, Chen S, Spilgies LM, Lieben L, Carmeliet G, Ansems M, Adema GJ. 2014. Vitamin D controls murine and human plasmacytoid dendritic cell function. J Invest Dermatol 134: 
1255-1264

20) Prietl B, Treiber G, Pieber TR, Amrein K. 2013. Vitamin $\mathrm{D}$ and immune function. Nutrients 5: 2502-2521.

21) La Cava A, Matarese G. 2004. The weight of leptin in immunity. Nat Rev Immunol 4: 371-379.

22) Saucillo DC, Gerriets VA, Sheng J, Rathmell JC, Maciver NJ. 2014. Leptin metabolically licenses T cells for activation to link nutrition and immunity. J Immunol 192: 136-144.

23) Moraes-Vieira PM, Larocca RA, Bassi EJ, Peron JP, Andrade-Oliveira V, Wasinski F, Araujo R, Thornley T, Quintana FJ, Basso AS, Strom TB, Camara NO. 2014. Leptin deficiency impairs maturation of dendritic cells and enhances induction of regulatory T, Th17 cells. Eur J Immunol 44: 794-806.

24) Lord GM, Matarese G, Howard JK, Baker RJ, Bloom SR, Lechler RI. 1998. Leptin modulates the T-cell immune response and reverses starvation-induced immunosuppression. Nature 394: 897-901.

25) Ye M, Bian LF. 2018. Association of serum leptin levels and pulmonary tuberculosis: a meta-analysis. J Thorac Dis 10: 1027-1036.

26) Perna V, Perez-Perez A, Fernandez-Riejos P, Polo-Padillo J, Batista N, Dominguez-Castellano A, Sanchez-Margalet V. 2013. Effective treatment of pulmonary tuberculosis restores plasma leptin levels. Eur Cytokine Netw 24: $157-161$.

27) Restrepo BI, Schlesinger LS. 2014. Impact of diabetes on the natural history of tuberculosis. Diabetes Res Clin Pract 106: 191-199.

28) Kumar NP, Banurekha VV, Nair D, Kumaran P, Dolla CK, Babu S. 2015. Type 2 diabetes-Tuberculosis co-morbidity is associated with diminished circulating levels of IL-20 subfamily of cytokines. Tuberculosis (Edinb) 95: 707-712.

29) Dooley KE, Chaisson RE. 2009. Tuberculosis and diabetes mellitus: convergence of two epidemics. Lancet Infect Dis 9: 737-746.

30) Kumar Nathella P, Babu S. 2017. Influence of diabetes mellitus on immunity to human tuberculosis. Immunology 152: 13-24.

31) Zhou B. 2002. Predictive values of body mass index and waist circumference to risk factors of related diseases in Chinese adult population. Zhonghua Liu Xing Bing Xue Za Zhi 23: 5-10 (in Chinese).

32) Wang Q, Ma A, Han X, Zhang H, Zhao S, Liang H, Cai J, Kok FJ, Schouten EG. 2017. Is low serum 25-hydroxyvitamin D level a possible link between pulmonary tuberculosis and type 2 diabetes? Asia Paci J Clin 26: 241-246.

33) Holick MF. 2007. Vitamin D deficiency. N Engl J Med 357: 266-281.

34) Pedersen BK. 2017. Anti-inflammatory effects of exercise: role in diabetes and cardiovascular disease. Eur J Clin Invest 47: 600-611.
35) Garbossa SG, Folli F. 2017. Vitamin D, sub-inflammation and insulin resistance. A window on a potential role for the interaction between bone and glucose metabolism. Rev Endocr Metab Disord 18: 243-258.

36) Lee TH, Jeon WS, Han KJ, Lee SY, Kim NH, Chae HB, Jang CM, Yoo KM, Park HJ, Lee MK, Park SE, Oh HG, Park CY, Lee WY, Oh KW, Park SW, Rhee EJ. 2015. Comparison of serum adipocytokine levels according to metabolic health and obesity status. Endocrinol Metab (Seoul) 30: 185-194.

37) Wang Q, Liu Y, Ma Y, Han L, Dou M, Zou Y, Sun L, Tian H, Li T, Jiang G, Du B, Kou T, Song J, Kok FJ, Schouten EG. 2018. Severe hypovitaminosis D in active tuberculosis patients and its predictors. Clin Nutr 37: 1034-1040.

38) Al-Daghri NM, Rahman S, Amer OE, Al-Attas OS, McTernan PG, Alokail MS. 2015. Gender dependent association of 25-hydroxyvitamin D and circulating leptin in saudi subjects: influence of dyslipidemia. Int J Clin Exp Med 8: 11160-11166.

39) Procaccini C, Jirillo E, Matarese G. 2012. Leptin as an immunomodulator. Mol Aspects Med 33: 35-45.

40) Cassano S, Pucino V, La Rocca C, Procaccini C, De Rosa V, Marone G, Matarese G. 2014. Leptin modulates autophagy in human CD4+CD25- conventional T cells. Metabolism 63: 1272-1279.

41) Hajimohammadi M, Shab-Bidar S, Neyestani TR. 2017. Vitamin D and serum leptin: a systematic review and meta-analysis of observational studies and randomized controlled trials. Eur J Clin Nutr 71: 1144-1153.

42) Arnedo-Pena A, Juan-Cerdan JV, Romeu-Garcia MA, Garcia-Ferrer D, Holguin-Gomez R, Iborra-Millet J, Pardo-Serrano F. 2015. Vitamin D status and incidence of tuberculosis infection conversion in contacts of pulmonary tuberculosis patients: a prospective cohort study. Epidemiol Infect 143: 1731-1741.

43) Lim S, Kim MJ, Choi SH, Shin CS, Park KS, Jang HC, Billings LK, Meigs JB. 2013. Association of vitamin D deficiency with incidence of type 2 diabetes in high-risk Asian subjects. Am J Clin Nutr 97: 524-530.

44) Zambuzi FA, Cardoso-Silva PM, Espindola MS, Soares LS, Galvao-Lima LJ, Brauer VS, Gomes MS, Amaral LR, Schaller M, Bollela VR, Frantz FG. 2016. Identification of promising plasma immune biomarkers to differentiate active pulmonary tuberculosis. Cytokine 88: 99-107.

45) Harishankar M, Afsal K, Banurekha VV, Meenakshi N, Selvaraj P. 2014. 1,25-Dihydroxy vitamin D3 downregulates pro-inflammatory cytokine response in pulmonary tuberculosis. Int Immunopharmacol 23: 148-152.

46) Eklund D, Persson HL, Larsson M, Welin A, Idh J, Paues J, Fransson SG, Stendahl O, Schon T, Lerm M. 2013. Vitamin D enhances IL-1beta secretion and restricts growth of Mycobacterium tuberculosis in macrophages from TB patients. Int J Mycobacteriol 2: 18-25. 